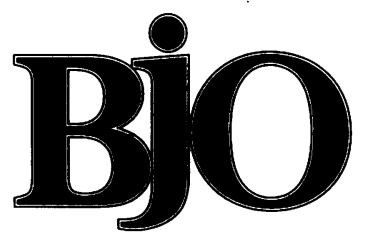

British Journal of Ophthalmology

Trachoma is still the most common cause of preventable blindness and loss of vision in the world despite decades of research and interventions for its control. According to a recent estimation active trachomatous inflammatory disease probably affects 146 million people, ${ }^{1}$ and close to six million people may be blind or severely visually disabled from trachoma and associated ocular infections. ${ }^{2}$

The relation between trachoma and socioeconomic settings is well known and should not be forgotten. Trachoma was endemic in many European countries well into this century, and was common in immigrants heading for the USA in the early 1900 s. However, the disease started to disappear from most European countries well before the era of antibiotics, simply because of better standards of living and hygiene. ${ }^{3}$

Trachoma was one of the diseases tackled by the World Health Organisation soon after its inception in 1948. The initial optimism of global control was, however, soon replaced by the realisation of the considerable research needed before any such scenario could be developed. Nevertheless, following large scale field trials in north Africa and the Middle East in the 1950s the WHO, together with the United Nations Children's Fund (UNICEF), embarked on mounting trachoma control campaigns in many countries where the disease was endemic during the 1960 s and 1970s. The results of these campaigns were often quite good in the short term, ${ }^{4}$ but maintenance of operations and the frequent lack of concomitant socioeconomic progress in the target areas led to problems for the long term control of the disease. The primary healthcare approach to eye care lends itself well to trachoma control, but this has not been fully implemented by today's endemic countries, particularly not in the poorest and most remote areas where trachoma is likely to be prevalent.

Building on the experience gained, the WHO Programme for the Prevention of Blindness has developed and simplified strategies for trachoma control. The assessment of clinical signs of trachoma has been greatly facilitated ${ }^{5}$ and surgical procedures for correction of trichiasis/entropion have been evaluated and standardised. ${ }^{6}$ Finally, the very important mobilisation of community support for trachoma control has been addressed as part of a comprehensive SAFE (surgery, antibiotics, face washing, and environmental hygiene) strategy. These developments, partially undertaken in collaboration with the Edna McConnell Clark Foundation, have resulted in a growing interest in trachoma control on a long term sustainable basis.

The work of Katz and collaborators in Nepal, presented in this issue of the BFO (p 1037), underlines the studies needed for an updated and correct understanding of the epidemiology of trachoma. The issue of 'blinding' and 'non-blinding' trachoma has long been recognised, but the specific risk factors and determinants for blinding disease have not been sufficiently described. For instance, the relation between water availability and utilisation patterns is more complex than previously realised, and the effects of possible interventions to improve personal or environmental hygiene need to be assessed. ${ }^{78}$ Thus, the great value of studies such as the one by Katz and collaborators lies in their epidemiological analysis of the determinants of trachomatous disease in children. More studies of this kind are needed to cover the varying public health scenario needed for successful trachoma control. However, as pointed out by the authors, their study is only giving a snapshot of inflammatory disease in children and several questions remain unanswered, particularly as to household transmission and blinding potential of the disease. The latter issue is complex, as changes in society with regard to social and economic circumstances may rapidly modify the picture of active disease in children, with adults and elderly reflecting blinding disease of the past. From a public health point of view, the whole range of disease pattern must be taken into account for the planning of interventions from antibiotic treatment to trichiasis surgery.

The recent availability of azithromycin against trachoma has opened up new opportunities for control of the disease, perhaps even in a global perspective. Azithromycin has been shown in several studies to have an outstanding effect on inflammatory trachoma, with a single dose $(30 \mathrm{mg} / \mathrm{kg})$ being as effective as a topical tetracycline treatment course over several weeks. ${ }^{9}$ Although there is still a need for research as to optimal dosage, it seems clear that azithromycin could make possible a breakthrough in trachoma control.

This was also the opinion of the participants of a recent WHO global scientific meeting on future approaches to trachoma control, but provided azithromycin can be made available to all those populations in need, on an affordable and sustainable basis. This may well be possible if the right formula of partnership between the manufacturer, the interested non-governmental organisations, WHO and other agencies, and the endemic countries can be found. Let us hope that such a partnership can become real and offer the opportunity, finally, for global elimination of trachoma as a public health problem.

B THYLEFORS

Programme for the Prevention of Blindness and Deafness, World Health Organisation, 1211 Geneva 27, Switzerland 
1 Thylefors B, Négrel AD, Pararajasegaram R. La surveillance épidémiologique du trachome: bilan et perspective. Rev Int Trachome 1992;69:107-14.

2 Thylefors B, Négrel AD, Pararajasegaram R, Dadzie KY. Global data on blindness. Bull World Health Organ 1995;73:115-21.

3 World Health Organisation. World distribution and prevalence of trachoma in recent years. Epidemiological and vital statistics report 1949. NovemberDecember. Geneva: WHO.

4 Thylefors B. Development of trachoma control programmes and the involvement of national resources. Rev Infect Dis 1985;7:774-6.

5 Thylefors B, Dawson CR, Jones BR, West SK, Taylor HR. A simplified sys-

tem for the assessment of trachoma and its complications. Bull World Health Organ 1987;65:477-83.

6 Reacher MH, Taylor HR. The management of trachomatous trichiasis. Rev
Int Trachome 1990;67:233-61.

7 West S, Muñoz B, Lynch M, Kayongoya A, Chilongwa A, Mmbaga BBO, et al. Impact of facewashing on trachoma in Kongwa, Tanzania. Lancet 1995; 345:155-8.

8 Courtright P, Sheppard J, Lane S, Sadek A, Schachter J, Dawson CR. Latrine ownership as a protective factor in inflammatory trachoma in Egypt. Br $\mathcal{F}$ Ophthalmol 1991:75:322-5.

9 Bailey RL, Arullandran P, Whittle HC, Mabey DCW. Randomised controlled trial of single-dose azithromycin in treatment of trachoma. Lancet 1993;342:453-6.

10 Tabbara KF, Abu El-Asrar AM, Al-Omar O, Choudhury AH, Al-Faisal Z. Single-dose azithromycin in the treatment of trachoma. Ophthalmology 1996;103:842-6.

\section{Retrobulbar pressures in dysthyroid optic neuropathy}

In their article entitled 'Retrobulbar pressures measured during surgical decompression of the orbit', the team from the Netherlands has produced a paper ( $p$ 1042) that is interesting as much for the questions it asks as for the answers it proposes. By direct measurement of orbital pressures in patients with Graves' orbitopathy, they have shown a raised retrobulbar pressure with dysthyroid optic neuropathy (DON) and a decrease in this pressure of 8-12 $\mathrm{mm} \mathrm{Hg}$ with orbital decompression. They therefore postulate that nerve dysfunction may not be exclusively the result of direct swelling of the extraocular muscles on the optic nerve but an effect of raised retrobulbar pressure on the optic nerve. In many ways, this is an attractive concept which helps to explain other features of DON, such as the dilated superior ophthalmic vein (and associated congestion which disappears rapidly after decompression) and the dilated retrobulbar optic nerve sheath. ${ }^{1}$ This work supports the concept of an orbital compartment syndrome described by Kratky et al and Hurwitz et al. ${ }^{23}$ It is also useful to explain the proposal of Trokel et al ${ }^{4}$ that anterior fat excision alone may reverse DON. ${ }^{5}$ Further experiments along this line would be useful and could include evaluation of the size of the drop in orbital pressure following fat excision alone and other decompressions, as well as indirect evidence of decrease in size of the superior ophthalmic vein and retrobulbar optic nerve sheath following decompression. Another feature that may be worth assessing is whether or not pressure correlates with the number of walls decompressed at the time of surgery.

As an aside, the authors note a dramatic rise in intraorbital pressure brought about by compression of orbital structures with instrumentation at the time of surgery, a feature that cautions care during retrobulbar procedures.

Their concept may not explain the small, tight orbit syndrome associated with optic neuropathy, which appears to result primarily from apical compression by swollen extraocular muscles in a disproportionately small orbital apex as is noted in some patients, particularly Asians. It also does not explain cases of persistent optic neuropathy following adequate release of orbital pressure. These cases appear to be the result of persistence of apical bone and require a secondary procedure to relieve the direct pressure brought about by the disproportion between soft tissue and bone.
What is harder to understand is their concept of fat protrusion into the optic canal as a cause of dysthyroid optic neuropathy. For anyone who has dissected the orbital apex, either in a cadaver or in the operating room, it is hard to imagine protrusion of fat through the very tight adherence of the annulus of Zinn to the apical optic nerve. The tissues here are absolutely intimate. This would suggest that their concept of direct orbital pressure comes into play just anterior to the annulus. Further, the dense retinacular network of the orbit described by Koornneef ${ }^{6}$ increases apically, which would tend to loculate fat and not allow for much movement of orbital contents posteriorly.

Their line of work is most interesting and suggests that non-invasive methods of direct orbital pressure measurement would be extremely useful in defining the critical point in orbital pressure that leads to optic neuropathy. It would also help to explain differences in effect on optic nerves of acute versus chronic orbital pressure, where down regulation may be a factor. ${ }^{7}$ The fact that orbital volume can show signs of having increased with contouring of the orbital wall brought about by volume and pressure changes is another feature that suggests raised orbital pressure is of significance on a chronic basis in DON, and with Graves' orbitopathy in general.

JACK ROOTMAN

University of British Columbia,

Vancouver, British Columbia,

Canada

1 Nugent RA, Belkin RI, Neigel JM, Rootman J, Robertson WD, Spinelli J, et al. Graves orbitopathy: correlation of CT and clinical findings. Radiology 1990;177:675-82.

2 Kratky V, Hurwitz J, Avram DR. Orbital compartment syndrome. Direct measurement of orbital tissue pressure: 1 Technique. Can $\mathcal{F}$ Ophthalmol 1990;25:293-7.

3 Hurwitz JJ, McGowan HD, Gentles W, Weise RA, Victor W. Orbitotonography, the dynamic assessment of orbital tension: 2 Results in patients

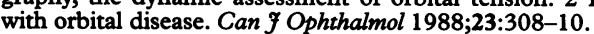

4 Trokel S, Kazim J, Moore S. Orbital fat removal. Decompression for Graves' orbitopathy. Ophthalmology 1993;100:674-82.

5 McGowan HD, Hurwitz JJ, Gentles W. Orbitotonography, the dynamic assessment of orbital tension: 1 Results in subjects without known orbital disease. Can $\mathcal{F}$ Ophthalmol 1984;13:122-5.

6 Koornneef L. Orbital septa: anatomy and function. Ophthalmology 1979;86: 876-80.

7 Otto AJ, Spekreijse H. Volume discrepancies in the orbit and the effect on the intra-orbital pressure. Orbit 1989;8:233-44. 